terms in the multiple choice questions. It think that if these and other equivocal words are clarified by the Examination Board one would find a narrowing in the gap between the British doctors' and the foreign postgraduate doctors' examination results.

The Old Manor Hospital

Wilton Road, Salisbury

A. Alanl

\section{Psychiatrists and political movements}

\section{DEAR SIRS}

I would like to sound a note of caution in relation to identifying psychiatrists with political movements. I was delighted to note that Dr Maclay (Psychiatry and the Peace Movement Bulletin, April 1986, 10, 83-84) and Professor Clare, when inviting psychiatrists to support the Nuclear Freeze Organisation, have not suggested a psychiatric parallel to International Physicians for Prevention of Nuclear War. As an early and enthusiastic member of the Doctors and Overpopulation Group, and supporter of nuclear freeze, I believe it is important to distinguish causes where doctors and psychiatrists have a special responsibility (e.g. the provision of contraception, and the use of psychiatry to detain political dissidents) and ones where our views are no more valid and relevant as others outside our profession. I expect most psychiatrists would be actively involved in political movements as an expression of their concern for the community as a whole.

Were one to link a political view with a group of psychiatrists the object would be to promote that cause by increasing publicity under the impression that the views of psychiatrists should be adopted by others. Our patients are by their very nature disordered in their thinking and may have views diametrically opposed to ourselves. Such patients should not come to psychiatrists reinforced in the belief that psychiatrists have attitudes and beliefs antithetical to their own. Thus the very effectiveness of such a link would reduce the clinical potential of psychiatric treatment, quite apart from increasing the barrier against psychiatric consultation.

JOHN M. KeLLETT

The Chalet

Mount Gardens

London SE26

\section{Approval under Section 12(2) of the Mental Health Act 1983}

Dear SIRS

Over the past few years I have come across approved doctors of some seniority who did not show the degree of grasp of the most essential provisions of the Mental Health Act that one would have expected of them.
I would therefore like to suggest that in order for the approval of Psychiatrists under Section 12(2) to have the most meaning, not only should applicants for approval be Members of the College (which I understand is already the case), but that they should also be required to show their understanding of the Mental Health Act by way of an oral test set up by the Regional Health Authority concerned. This way we would know that those who are approved actually do have experience in the diagnosis and treatment of mental disorders and are also confident in interpreting and applying the various provisions of the Mental Health Act.

I. O. AZUONYE

Locum Consultant Psychiatrist

St Augustine's Hospital

Canterbury, Kent

\section{Consultants and administrators}

\section{DeAr Sirs}

Sitting in a recent senior medical staff committee, listening to an animated and rather chaotic discussion of the impact of recent ward closure and cost cutting exercises, I was struck by the similarity to a recent marital situation which I have been treating.

In this case the consultants represent the injured party (the woman). They are hot-headed, temperamental, prone to hyperbole and exaggeration, while feeling ignored and helpless. They feel their patients (the children) are suffering at the hands of the stingy budget-dominated administrators whose callous disregard for patients wellbeing is hidden behind an inscrutable mask of calm control (the husband).

As in the marital situation, the administrators regard the consultants as irresponsible, over-emotional, chaotic, lacking in judgement, and unable to manage. They perceive themselves as balanced, rational and in command. They harbour fears of wildly extravagant behaviour were the consultants ever to have free rein with the money.

Maritally this dynamic is common. This is because it receives social sanction, conforming as it does to stereotyped views of sex role behaviour. In the relationship the woman is defined as a child and the man her controlling father. She loses her sense of responsibility and control over her own destiny in exchange for care and protection provided by her husband. Unfortunately, the less benign aspects of the relationship involve a progressive loss of self-respect, demoralisation and depression. Because of the interdependence which develops there is an apportionment of qualities between the couple with each needing the other to contain unwanted aspects of themselves. This is referred to as projective identification.

With the passage of time each person's behaviour becomes exaggerated like a caricature. The woman is overemotional as she carries her husband's unwanted passions which allow him to stay calm and in control. The man is rocklike and unfeeling as a result. Outbursts by the woman 